\title{
PENDIDIKAN IBU BERHUBUNGAN DENGAN PEMBERIAN ASI EKSKLUSIF
}

\author{
Cik Angkut \\ *Stikes Prima Indonesia Bekasi \\ email: cikyoes@gmail.com
}

\begin{abstract}
Background ASI is an essential nutrient that is needed by babies for growth and mental and intellectual development and increase endurance against various diseases. reality on the ground shows different results than they should. Based on data from the West Java Health Office, exclusive breastfeeding coverage for infants aged 0 - 6 months in 2013 was 30.2\% in West Java. (West Java Health Service, 2013). This indicates the lack of exclusive breastfeeding for infants in the area of West Java. Exclusive breastfeeding in Bekasi City is still relatively low and has not reached the target of only around $24.2 \%$. While the target of exclusive breastfeeding success rate is $75 \%$

The purpose of this study is to determine the relationship of maternal education to exclusive breastfeeding at the Pejuang Health Center in Bekasi City in 2019

The research method used was an analytical survey with cross sectional research design. The population of mothers who have babies aged 6 months to 24 months amounted to 79 people with a sample of 47 people with accidental sampling techniques. Analysis of the data used Univariate and Bivariate

Result Univariate research results contained mothers with low education as much as $59.6 \%$ and mothers with higher education as much as $40.4 \%$. Furthermore, there were mothers who did not give exclusive breastfeeding as much as $46.8 \%$ and $53.2 \%$ of mothers who provided exclusive breastfeeding. Furthermore, from the results of the Bivariat study, the ratio between mothers who gave exclusive breastfeeding was $53.2 \%$ and mothers who did not give exclusive breastfeeding was $46.8 \%$ with a $P$ value of 0.406 . This means that there is little relationship between the level of maternal education with exclusive breastfeeding to infants.

The conclusion of this study shows that in addition to the level of education, support and information from health workers and families regarding breastfeeding for mothers is needed in increasing the intelligence and skills of mothers to provide exclusive breastfeeding to infants.

Suggestions For research sites to pay more attention to the role of health workers in an effort to provide awareness to nursing mothers to maximize exclusive breastfeeding to their babies. Because the role of health workers affects the awareness of nursing mothers.
\end{abstract}

Keywords: Education, ASI, Exclusive, ASI Information, Health Officers, Family.

\section{ABSTRAK}

Latar Belakang Asi Eksklufif adalah nutrisi yang sangat dibutuhkan oleh bayi untuk pertumbuhan dan perkembangan mental dan intelektual serta meningkatkan daya tahan tubuh terhadap berbagai penyakit. kenyataan di lapangan menunjukkan hasil yang berbeda dari yang seharusnya. Berdasarkan data Dinas Kesehatan Jawa Barat, cakupan ASI Eksklusif pada bayi usia 0 - 6 bulan tahun 2013 adalah sebanyak 30,2\% seJawa Barat. (Dinas Kesehatan Jawa Barat, 2013). Hal tersebut mengindikasikan kurangnya pemberian ASI eksklusif pada bayi di daerah Jawa Barat.Pemberian ASI Eksklusif di Kota Bekasi masih terbilang rendah dan belum mencapai target yaitu hanya sekitar 24,2\%. Sedangkan target angka keberhasilan ASI Eksklusif sebesar $75 \%$

Tujuan untuk mengetahui hubungan pendidikan ibu terhadap pemberian ASI Ekskusif di Puskesmas Pejuang Kota Bekasi Tahun 2019.

Metode penelitian yang digunakan adalah survei analitik dengan desain penelitian Cross Sectional Populasi ibu yang mempunyai bayi usia 6 bulan sampai dengan 24 bulan berjumlah 79 orang dengan sampel sebanyak 47 orang dengan tekhnik sampling accidental. Analisa data yang digunakan Univariat dan Bivariat

Hasil penelitian Univariat terdapat ibu dengan pendidikan rendah sebanyak $59,6 \%$ dan ibu dengan pendidikan tinggi sebanyak 40,4\%. Selanjutnya terdapat ibu yang tidak memberikan ASI Eksklusif sebanyak $46,8 \%$ dan terdapat $53,2 \%$ ibu yang memberikan ASI Ekskusif. Selanjutnya dari hasil peneltian Bivariat, perbandingan antara ibu yang memberikan ASI Ekslusif sebesar $53,2 \%$ dengan ibu yang tidak memberikan ASI 
Eksklusif sebesar $46,8 \%$ dengan $P$ Value 0,406 . Artinya hanya sedikit hubungan antara tingkat pendidikan ibu dengan pemberian ASI ekslusif kepada bayi.

Kesimpulan penelitian ini menunjukkan bahwa selain tingkat pendidikan, dukungan dan informasi dari petugas kesehatan dan keluarga mengenai pemberian ASI pada ibu diperlukan dalam menambah kecerdasan dan keterampilan ibu untuk memberikan ASI Ekskusif pada bayi.

Saran Bagi tempat penelitian agar lebih diperhatikan peran serta petugas kesehatan dalam upaya memberikan kesadaran kepada Ibu menyusui untuk memaksimalkan pemberian ASI Eksklusif kepada bayinya. Karena peran petugas kesehatan berpengaruh kepada kesadaran Ibu menyusui.

Kata Kunci : Pendidikan, ASI, Eksklusif, Informasi ASI, Petugas Kesehatan, Keluarga.

\section{PENDAHULUAN}

ASI Eksklufif adalah nutrisi yang sangat dibutuhkan oleh bayi untuk pertumbuhan dan perkembangan mental dan intelektual serta meningkatkan daya tahan tubuh terhadap berbagai penyakit. ASI Eksklusif diberikan kepada bayi sejak dilahirkan selama 6 bulan, tanpa menambahkan dan atau mengganti dengan makanan atau minuman lain. (KEMENKES RI Nomor 15 Tahun 2013).

Pemberian ASI Ekslusif menjadi salah program pemerintah untuk membangun kualitas sumber daya manusia Indonesia yang kuat dan berkualitas di masa mendatang sesuai dengan peraturan pemerintah no. 33 tahun 2012 tentang kewajiban ibu untuk memberikan ASI pada bayinya secara Eklusif. ASI Eksklusif adalah pemberian ASI saja sejak bayi dilahirkan selama 6 bulan tanpa menambahkan atau menganti dengan makanan atau minuman lain (kecuali obat, vitamin dan mineral).

Namun kenyataan di lapangan menunjukkan hasil yang berbeda dari yang seharusnya. Berdasarkan data Dinas Kesehatan Jawa Barat, cakupan ASI Eksklusif pada bayi usia 0 - 6 bulan tahun 2013 adalah sebanyak 30,2\% se-Jawa Barat. (Dinas Kesehatan Jawa Barat, 2013). Hal tersebut mengindikasikan kurangnya pemberian ASI eksklusif pada bayi di daerah Jawa Barat.

Pemberian ASI Eksklusif di Kota Bekasi masih terbilang rendah dan belum mencapai target yaitu hanya sekitar $24,2 \%$. Sedangkan target angka keberhasilan ASI Eksklusif sebesar 75\% (Dinkes, Jawa Barat 2016). Banyak faktor yang menyebabkan rendahnya cakupan pemberian ASI Eklusif di Kota Bekasi, salah satunya disebabkan tingkat pendidikan ibu yang rendah (< SMU) sebesar 42,1\% (Kusuma Dini, 2013).

Berdasarkan uraian di atas, penulis tertarik untuk meneliti lebih lanjut tentang hubungan pendidikan dan perilaku ibu dalam memberikan ASI Eksklusif di Puskesmas Pejuang Kota Bekasi Tahun 2019.

\section{METODE PENELITIAN}

Jenis penelitian ini adalah penelitian survey analitik dengan rancangan cross sectional study. Penelitian ini telah dilaksanakan di Puskesmas Pejuang Kota Bekasi Tahun 2019.

Populasi ibu yang mempunyai bayi usia 6 bulan sampai dengan 24 bulan di puskesmas Pejuang Kota Bekasi Tahun 2019 berjumlah 79 orang dengan sampel sebanyak 47 orang Teknik pengambilan sampel yang digunakan dalam penelitian ini adalah Purposive Sampling yaitu berdasarkan kriteria yang telah ditentukan

Instrumen pengumpulan data adalah kuesioner. Pengumpulan data meliputi data primer tentang pendidikan ibu dan menyusui ASI eksklusif

Data yang telah dikumpulkan diinput ke komputer dan dianalisis menggunakan program SPSS 22. Analisis data dilakukan secara deskriptif dan analitik. Secara deskriptif data disajikan dalam bentuk tabel distribusi frekuensi disertai penjelasan dan persentase. Sedangkan untuk menganalisis hubungan variabel antara pemberian ASI eksklusif dan BBLR dengan kejadian stunting pada balita usia 12-36 bulan menggunakan uji chi-Square.

\section{HASIL}

Penelitian menggunakan metode survei analitik dengan desain penelitian Cross Sectional Populasi ibu yang mempunyai bayi usia 6 bulan sampai dengan 24 bulan berjumlah 79 orang dengan asampel sebanyak 47 orang dengan tekhnik sampling accidental. Analisa data yang digunakan Univarriat dan Bivariat dengan chi Square.

\section{HASIL PENELITIAN \\ Analisa Univariat}

Tabel dibawah menggambarkan bahwa dari total keseluruhan sampel yaitu 47 ibu yang memiliki bayi dengan kriteria $\geq 6$ - 24 bulan, terdapat 28 ibu ( $59,6 \%$ ) yang berpendidikan rendah dan terdapat 19 ibu ( $40,4 \%)$ yang berpendidikan tinggi. 
Tabel 1.

Distribusi Frekuensi berdasarkan Pendidikan Ibu di Puskesmas Pejuang Tahun 2019

\begin{tabular}{ccc}
\hline Pendidikan & Frekuensi & Persentasi $(\%)$ \\
\hline Rendah & 28 & $59,6 \%$ \\
Tinggi & 19 & $40,4 \%$ \\
\hline Total & 47 & $100 \%$ \\
\hline
\end{tabular}

Pada tabel 2 Analisa Univariat dapat dilihat bahwa dari total keseluruhan sampel yang diteliti yaitu 47 ibu yang memiliki bayi dengan kriteria $\geq 6$ 24 bulan terdapat 22 ibu $(46,8 \%)$ yang tidak memberikan ASI Eksklusif dan 25 ibu $(53,2 \%)$ yang memberikan ASI Eksklusif.

Tabel 2.

Distribusi Frekuensi berdasarkan pemberian ASI Eksklusif di Puskesmas Pejuang Tahun 2019

\begin{tabular}{|c|c|c|}
\hline $\begin{array}{c}\text { Pemberian } \\
\text { ASI Eksklusif }\end{array}$ & Frekuensi & Persentase (\%) \\
\hline $\begin{array}{l}\text { Tidak ASI } \\
\text { Fksklusif }\end{array}$ & 22 & $46,8 \%$ \\
\hline ASI Eksklusif & 25 & $53,2 \%$ \\
\hline Total & 47 & $100 \%$ \\
\hline
\end{tabular}

\section{Analisa Bivariat}

Tabel 3.

Hubungan Antara Pendidikan Ibu Terhadap Pemberian ASI Eksklusif di Puskesmas Pejuang Tahun 2019

\begin{tabular}{cccccccc}
\hline \multirow{2}{*}{ Pendidikan } & \multicolumn{3}{c}{ Pemberian ASI Eksklusif } & & \multirow{2}{*}{ Total } & \multirow{2}{*}{ P Value } \\
\cline { 2 - 5 } & \multicolumn{2}{c}{ Tidak ASI Eksklusif } & \multicolumn{2}{c}{ ASI Eksklusif } & & & \\
\cline { 2 - 7 } & $\mathrm{N}$ & $\%$ & $\mathrm{~N}$ & $\%$ & $\mathrm{~N}$ & $\%$ & \\
\hline Rendah & 15 & 28,7 & 13 & 27,0 & 28 & 59,6 & \multirow{2}{*}{0,406} \\
Tinggi & 7 & 18,1 & 12 & 26,2 & 19 & 40,4 & \\
\hline Total & 22 & 46,8 & 25 & 53,2 & 47 & 100 & \\
\hline
\end{tabular}

Dapat dilihat dari tabel diatas bahwa dari 3 sampel yang diteliti menunjukkan tingkat pendidikan rendah sebanyak 15 responden ( $28,7 \%$ ) tidak memberikan ASI Eksklusif dan tingkat pendidikan tinggi terdapat 7 responden ( $18,1 \%$ ). yang tidak memberikan ASI Ekslusif. Tingkat pendidikan rendah sebanyak 13 Responden (27,0\%) memberikan ASI Ekskulisf dan tingkat pendidikan tinggi sebanyak 12 responden ( $26,2 \%$ ) memberikan Asi Ekskulisif. Hasil koreksi $P$ Value 0,406 atau $<0,05$ dengan tingkat kepercayaan $95 \%$. Artinya pada penelitian ini tidak ada hubungan antara tingkat pendidikan ibu terhadap pemberian Asi Ekslusif di Puskesmas Pejuang Kota Bekasi Tahun 2019.

\section{PEMBAHASAN}

Berdasarkan hasil penelitian di atas menunjukkan bahwa tidak ada hubungan antara tingkat pendidikan Ibu terhadap pemberian Asi Eksklusif di Puskesmas Pejuang Kota Bekasi.

Pendidikan mempengaruhi proses belajar, dimana makin tinggi pendidikan seseorang makin mudah orang tersebut untuk menerima informasi. Dengan pendidikan tinggi maka seseorang akan cenderung untuk mendapatkan informasi, baik dari orang lain maupun dari media masa, semakin banyak informasi yang masuk semakin banyak pula pengetahuan yang didapat tentang kesehatan (Notoatmodjo, 2007).

Pada penelitian ini ibu dengan tingkat pendidikan rendah lebih banyak yang tidak memberikan ASI Ekslusif sebesar 15 responden ( $28,7 \%$ ) dibandingkan dengan tingkat pendidikan tinggi yaitu hanya 7 responden ( $18,1 \%$ ) yang tidak memberikan ASI Eksklusif. Selanjutnya ibu dengan tingkat pendidikan tinggi memberikan ASI Eklusif sebanyak 12 responden ( 26,2\% ) dan ibu dengan tingkat pendidikan rendah sebesar 13 responden (27\%) yang memberikan ASI Eksklusif.

Hal ini didukung dengan teori bahwa seseorang dengan tingkat pendidikan yang tinggi makin mudah untuk menerima informasi dan mendapatkan sumber informasi (Notoatmodjo,2007 ). Selain dari sumber informasi, dukungan petugas kesehatan atau bidan pada saat ibu hamil melakukan pemeriksaan Ante Natal Care, dapat memberikan konseling tentang persiapan pemberian ASI Eksklusif sejak dini sehingga ibu hamil mempunyai pengetahuan yang cukup tentang manfaat ASI Eksklusif.

Hal ini sesuai dengan penyataan bahwa dukungan bidan dalam pemberian ASI Eklusif, sarana pelayanan kesehatan yang memiliki kebijakan tertulis mengenai pemberian ASI yang dikomunikasikan secara rutin, dan upaya terbentuknya kelompok pendukung ASI dan rujuk 
ibu kepada kelompok itu ketika pulang dari tempat bersalin. ( Ai Yeyeh Rukiyah, 2014).

\section{KESIMPULAN}

Berdasarkan hasil penelitian ini dapat disimpulkan bahwa ibu dengan tingkat pendidikan rendah sebanyak $28 \%$ tidak memberikan ASI Ekslusif kepada bayinya. Sedangkan ibu dengan tingkat pendidikan tinggi hanya $18 \%$ yang tidak memberikan ASI Eksklusif. Meski begitu, hasil $p$ value menunjukkan hanya sedikit pengaruh pendidikan terhadap frekuensi pemberian ASI Eksklusif ibu kepada bayi. Hal ini mengindikasikan bahwa selain pendidikan, dukungan keluarga dan juga dukungan petugas kesehatan akan mempengaruhi pemberian ASI Eksklusif Ibu kepada bayi.

\section{SARAN}

Bagi tempat penelitian agar lebih diperhatikan peran serta petugas kesehatan dalam upaya memberikan kesadaran kepada lbu menyusui untuk memaksimalkan pemberian ASI Eksklusif kepada bayinya. Karena peran petugas kesehatan berpengaruh kepada kesadaran Ibu menyusui.

Bagi Peneliti selanjutnya agar diperhatikan untuk melakukan pembahasan yang lebih luas terkait faktor - faktor lain yang menyebabkan kurangnya kesadaran Ibu untuk memberikan ASI Eksklusif kepada bayinya.

Bagi Responden agar menjadi bahan informasi dan edukasi terutama dalam meningkatkan kesadaran pentingnya ASI Eksklusif bagi bayi sampai umur 6 bulan untuk menjadikan bayi lebih kuat dan sehat di masa yang akan datang.

\section{DAFTAR PUSTAKA}

Maryunani, A. (2012). Inisiasi menyusui dini, ASI eksklusif dan manajemen laktasi. Jakarta: Trans Info Media.

Pangestika, E. (2016). HUBUNGAN TINGKAT PENDIDIKAN IBU DENGAN PRAKTIK
PEMBERIAN ASI EKSKLUSIF PADA IBU YANG MELAHIRKAN DI RSUD WATES KULON PROGO (Doctoral dissertation, STIKES Jenderal Achmad Yani Yogyakarta).

Prasetyono, S. (2016). ASI Eksklusif Pengenalan, Praktik, dan Kemanfaatan-Kemanfaatan.

Profil Kesehatan Kota Bekasi (2017) Bekasi: Dinas Kesehatan Kota Bekasi

Direktorat Bina Kesmas Direktorat Gizi Masyarakat Departemen Kesehatan (2014). Jakarta

Jannah, A. M. (2016). Faktor-Faktor yang berhubungan dengan perilaku pemberian asi eksklusif pada bayi usia 6-12 bulan di Kelurahan Gerem Wilayah Kerja Puskesmas Grogol Kota Cilegon Tahun 2015 (Bachelor's thesis, UIN Syarif Hidayatullah Jakarta: Fakultas Kedokteran dan IImu Kesehatan, 2016).

Notoatmodjo. 2014. Pendidikan dan Perilaku Kesehatan. Jakarta: Rineka Cipta

Notoatmodjo, S. (2010). Metodologi penelitian kesehatan.

UNICEF. 2012. Ringkasan Kajian Kesehatan Ibu dan Anak. Diunduh dari:www.unicef.org/indonesia/id/A5

Arikunto, S. (2010). Prosedur Penelitian Suatu Pendekatan Praktik, Jakarta: Rineka Cipta, Cet. Ke-13.

Sabri, L., \& Hastono, S. P. (2006). Statistik kesehatan. Edisi revisi. PT. Raja Grafindo Persada, Jakarta.

Septiani, H. U., Budi, A., \& Karbito, K. (2017). Faktor-faktor yang berhubungan dengan pemberian ASI eksklusif oleh ibu menyusui yang bekerja sebagai tenaga kesehatan. Aisyah: Jurnal IImu Kesehatan, 2(2), 217373.

Dini, K. (2017). Dukungan Ibu Mertua Dan Karakteristik lbu Terhadap Perilaku Pemberian ASI Eksklusif. Jurnal IImiah Wipya,[Online], 4(1).

Ahmadi, A., \& Salimi, N. (2008). Dasar-dasar Pendidikan Agama Islam, Cet. Ke-5, Jakarta: Bumi Aksara. 